\author{
Military Technical College \\ Kobry El-Kobbah, \\ Cairo, Egypt.
}

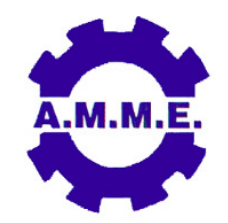
$17^{\text {th }}$ International Conference
on Applied Mechanics and
Mechanical Engineering.

\title{
PDF VERSUS PID CONTROLLER FOR ACTIVE VEHICLE SUSPENSION
}

\author{
Y. M. Elattar ${ }^{1}$, S. M. Metwalli ${ }^{2}$ and M. G. Rabie ${ }^{3}$
}

\begin{abstract}
The main objective of this work is to investigate the dynamic performance of vehicle active suspension systems. A design for quarter vehicle equipped with active suspension system is presented. The dynamic behavior of the system evaluated by developing a mathematical model for the controlled system and developing a computer simulation program. The system incorporates an electrohydraulic servo system controlled by a proportional, integral, derivative (PID) controller. Alternatively, a pseudo derivative feedback controller (PDF) is used. The parameters of both of the controllers were estimated and tuned to minimize the integrated of square error (ISE) and integral of time absolute error (ITAE) criterions. The proportional, derivative (PD) controller gave the shortest settling time. The PDF controller showed negligible maximum percentage overshoot. While the PID showed a maximum percentage overshoot within $5 \%$. The proportional, integral $(\mathrm{PI})$ and PD showed longer settling time.
\end{abstract}

\section{KEY WORDS}

Vehicle active suspension, PID, PDF, ISE, ITAE, Matlab, Simulink, shock absorber, modeling

Lecturer Assistant, Modern Academy for Engineering and Tech., Cairo, Egypt. Professor of Mech. Engineering, Faculty for Engineering, Cairo Univ., Egypt. Professor of Mech. Eng., Modern Academy for Eng. and Tech., Cairo, Egypt 


\section{NOMENCLATURE}

a Radius of free outer end of the circular plate, $(\mathrm{m})$

$A_{N} \quad$ Fixed throttling area of the hydro-pneumatic suspension, $\left(\mathrm{m}^{2}\right)$

$A_{N 1} \quad$ Variable throttling area 1 of the hydro-pneumatic suspension, $\left(\mathrm{m}^{2}\right)$

$A_{N 2}$ Variable throttling area 2 of the hydro-pneumatic suspension, $\left(\mathrm{m}^{2}\right)$

B Oil bulk modulus, $\left(\mathrm{N} / \mathrm{m}^{2}\right)$

b Radius of fixed inner end of the circular plate, $(\mathrm{m})$

$B_{c} \quad$ Constant of PDF first estimation, (A.s $/ m$ )

C Spring gas constant, (N.m)

$\mathrm{C}_{\mathrm{d}} \quad$ Discharge coefficient

Cs Shock absorber damping ratio

CT Tire damping ratio

D Flexural stiffness (or flexural rigidity)

E Material Young's modulus, $(\mathrm{Pa})$

$\mathrm{F} \quad$ Generated damping force, (N)

fo low cut-off frequency, $(\mathrm{Hz})$

G Gravitational acceleration, $\left(\mathrm{m}^{2} / \mathrm{s}\right)$

I Input current, (A)

ie Input current for EHSV, (A)

$\mathrm{J} \quad$ Maximum current step input for EHSV, (A)

$\mathrm{k}_{1} \quad$ Coefficient for circular plate deflection equation, $\left(2.3 \times 10^{-3} \mathrm{P}\right)$

$\mathrm{k}_{2} \quad$ Coefficient for circular plate deflection equation, $\left(-1.1 \times 10^{-7} \mathrm{P}\right)$

$\mathrm{k}_{3} \quad$ Coefficient for circular plate deflection equation, $\left(7.8 \times 10^{-8} \mathrm{P}\right)$

$\mathrm{K} \quad$ Gain of transfer function

$\mathrm{K}_{\mathrm{D}} \quad$ Feedback derivative coefficient

$\mathrm{K}_{\mathrm{i}} \quad$ Feedback integral coefficient

$K_{P} \quad$ Feedback proportional coefficient

Ks Spring stiffness, $(\mathrm{N} / \mathrm{m})$

$\mathrm{Ku} \quad$ Ultimate gain

M Maximum height of actuator connected to ESHV, $(\mathrm{m})$

Mr Radial moment, (N.m)

Ms $\quad$ Sprung mass, $(\mathrm{kg})$

$M_{t} \quad$ Circumferential moment on face, (N.m)

Mu Unsprung mass, $(\mathrm{kg})$

$\mathrm{P}_{\mathrm{N}} \quad$ Pressure at accumulator of hydro-pneumatic suspension, $\left(\mathrm{N} / \mathrm{m}^{2}\right)$

$P_{p} \quad$ Pressure at SA of hydro-pneumatic suspension, $\left(\mathrm{N} / \mathrm{m}^{2}\right)$

$Q \quad$ Shearing force per unit length of the plate middle plane

$Q_{a} \quad$ Flow rate at port $P$ in the EHSV, $\left(\mathrm{m}^{3} / \mathrm{s}\right)$

$\mathrm{Qb}_{b} \quad$ Flow rate at port T in the EHSV, $\left(\mathrm{m}^{3} / \mathrm{s}\right)$

$Q_{P} \quad$ Total flow rate in and out of the accumulator of the hydro-pneumatic suspension, $\left(\mathrm{m}^{3} / \mathrm{s}\right)$

QP1 Flow rate in throttling area $A_{c 1}$ of the SA of the hydro-pneumatic suspension, $\left(\mathrm{m}^{3} / \mathrm{s}\right)$

QP2 Flow rate in throttling area $A_{c 2}$ of the SA of the hydro-pneumatic suspension, $\left(\mathrm{m}^{3} / \mathrm{s}\right)$

QPo Total flow rate in throttling area Ac of the SA of the hydro-pneumatic suspension, $\left(\mathrm{m}^{3} / \mathrm{s}\right)$

$\mathrm{R} \quad$ Radius at which the deflection of the plate are calculated, (m)

$\mathrm{t} \quad$ Plate thickness, $(\mathrm{m})$

$\mathrm{T}_{\mathrm{d}} \quad$ Time derivative term for PID controller

$\mathrm{T}_{\mathrm{i}} \quad$ Time integral term for PID controller

$T_{r} \quad$ Rise time,(s)

$T_{s} \quad$ Settling time, (s) 
Uo Vehicle forward speed, $(\mathrm{m} / \mathrm{s})$

$V_{N} \quad$ volume of oil in accumulator of hydro-pneumatic suspension, $\left(\mathrm{m}^{3}\right)$

w Plate deflection at radius $r$

$\mathrm{X}_{1} \quad$ Displacement of un-sprung mass, $(\mathrm{m})$

$\mathrm{x}_{2} \quad$ Displacement of sprung mass, $(\mathrm{m})$

$x_{0} \quad$ Displacement of road profile, $(\mathrm{m})$

$\mathrm{Zd}_{\mathrm{d}} \quad$ Deflection of the circular thin plate, $(\mathrm{m})$

$\zeta \quad$ Damping ratio

$\vartheta \quad$ The slope (angle of rotation) at radius $r$

$\rho \quad$ Oil density, $\left(\mathrm{kg} / \mathrm{m}^{3}\right)$

$\sigma \quad$ Overshoot ratio

$\sigma_{t} \quad$ Circumferential stress, $(\mathrm{Pa})$

$\tau_{u} \quad$ Ultimate period of oscillation, (s)

$v \quad$ Poisson's ratio

$\omega n \quad$ Natural frequency of EHSV, $(\mathrm{Hz})$

\section{INTRODUCTION}

Active suspension system provides better ride comfort and vehicle stability. But it costs too much compared with semi-active or passive suspension systems. Active suspension system operates between the sprung and unsprung masses of the vehicle. It minimizes the vertical acceleration and the vibration of the vehicle caused by road and vehicle dynamics. It improves the vehicle handling and stability. Active suspension system comprises a hydraulic circuit, sensors, and a control system.

Most of the active suspensions, which have reached the stage of hardware development and production, have used some form of electrohydraulic actuator [1]. Two forms of active suspension are commonly recognized. The first is the fast active suspension or high-bandwidth system $(\mathrm{HB})$, often referred to as fully active. The second is the slow active suspension or low-bandwidth system (LB). In an active suspension, the passive damper or both the passive damper and spring are replaced with a force actuator, as illustrated in (Fig. 1).

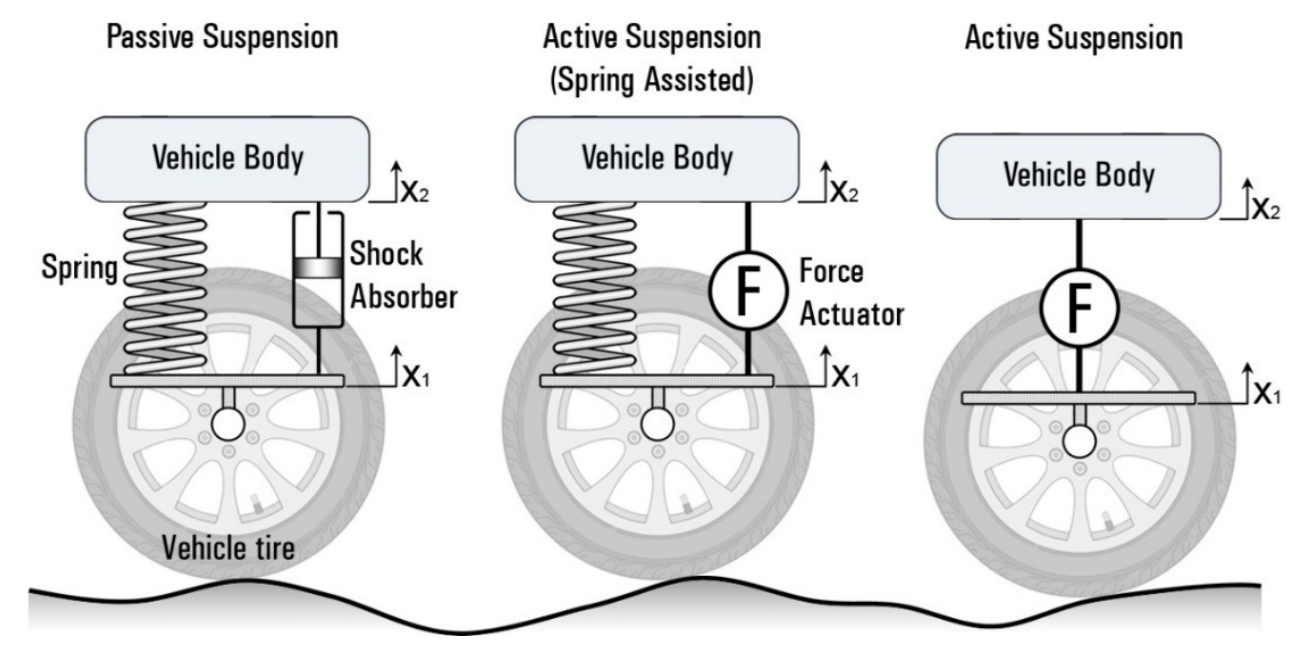

Fig. 1. Active suspension concept. 
Choosing the right control system, this outcomes in a superior compromise between ride comfort and vehicle stability when contrasted with a passive system, as indicated in (Fig. 2) for a quarter vehicle model [2].

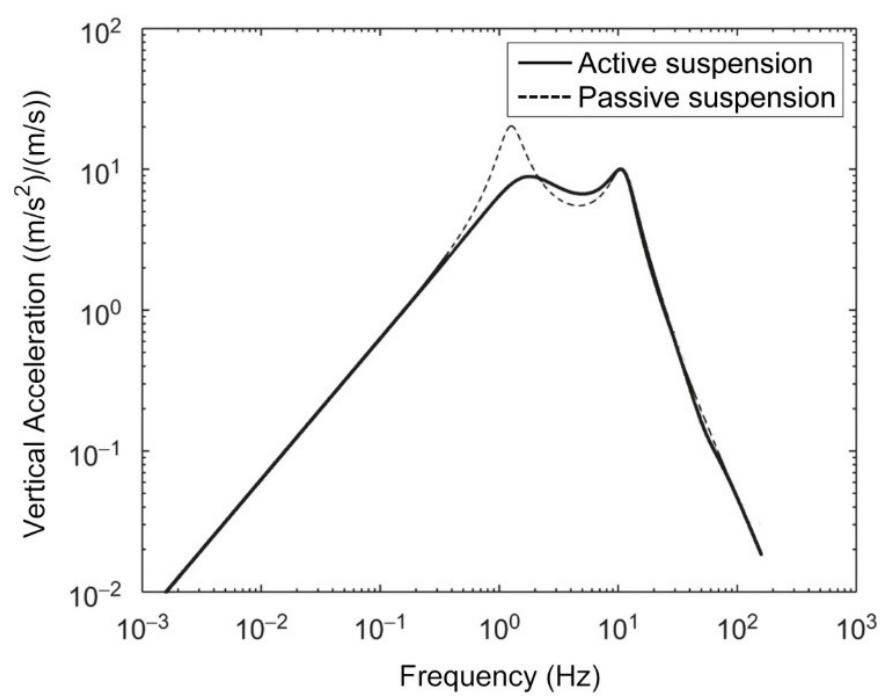

Fig. 2. Acceleration frequency response of active and passive suspensions [2].

\section{FULLY ACTIVE SUSPENSION SYSTEM (HIGH BANDWIDTH)}

Also known as high bandwidth has actuator placed between the sprung and unsprung masses (Fig. 3). The main function of high bandwidth system is control the system over the full bandwidth of the whole system. Specifically, this implies that it is aimed to enhance the suspension response around both of the rattle-space frequencies (from 10 to $12 \mathrm{~Hz}$ ) and tire-hop frequency (from 3 to $4 \mathrm{~Hz}$ ).

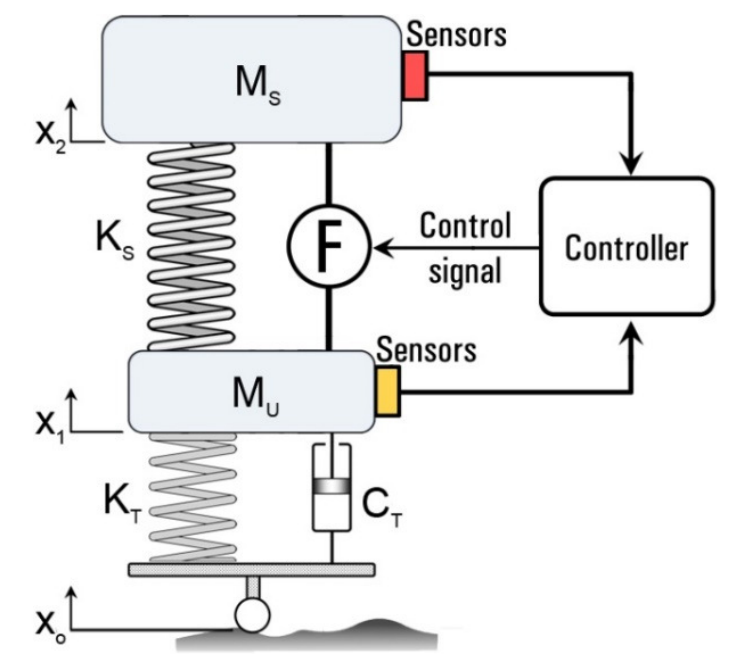

Fig. 3. High bandwidth active suspension system.

Satoh [3] built up an active suspension system utilizing an electrohydraulic servo system (EHS) and employed the pressure control valves which are requisitioned the 
first time through. The suspension is controlled by a microprocessor and acceleration sensors. They portrayed the theoretical and experimental analysis, which were led in building up this system. This system emphasizes a skyhook damper that can lessen body vibration more than the traditional suspensions at low frequencies. This fulfilled by applying active damping force to the body relative to its absolute velocity. The hydraulic system has a passive damping characteristic reliant on excitation frequencies of road inputs. Enhancement of these characteristics brings about a diminishment of vibration created by high frequency road surface inputs.

Williams [4] discussed the hardware employed in active suspension systems, which ranges from simple swished dampers, through semi-active dampers, and low bandwidth/soft active suspensions, to high bandwidth/stiff active suspensions. The benefits to be derived from each of the technologies are assessed, together with the practical implications. He concluded that adaptive and semi-active devices are an effective means of improving straight-line ride and handling transient performance. While the improvements they provide in ride are not as great as active suspensions.

\section{SLOW ACTIVE SUSPENSION SYSTEM (LOW BANDWIDTH)}

It is applicable to operate in low bandwidth operations. In this system the actuator is placed in series with spring and/or a damper. Slow active suspension system (operating in low band width less than $3 \mathrm{~Hz}$ ) is designed to fulfill a control policy of the suspension over the lower frequency range, and specifically around the rattle space frequency. At higher frequencies the actuator effectively locks-up and hence the wheelhop motion is controlled passively. Low bandwidth systems can achieve a worthy reduction in both body roll and pitch during maneuvers with lower energy consumption than a high bandwidth system [5].

To provide suspension action beyond the controlled bandwidth, the actuator must be mounted in series with a conventional spring, which in turn reduces the energy requirements of the system. Two forms of low-bandwidth system are considered, as shown in (Fig. 4), the form where the actuator sits in series with the road spring, and has a separate passive damper (LB1), the other form where the actuator sits in series with both the spring and damper (LB2). This form is investigated theoretically and experimentally in this study. In slow active suspension, the passive spring provides the required isolation at high frequencies while the actuator provides vibration control at low frequencies (usually below $3 \mathrm{~Hz}$ ).

The theoretical studies showed that the limited bandwidth active systems have a performance similar to that of fully active systems, but with reduced cost and complexity implementations [6]. These studies based on a quarter car model showed very modest power requirements when idealized components are assumed and vehicle is operating in a straight running condition.

Some possible practical implementations of this system have been proposed by using hydropneumatic components, such as a pneumatic spring with valves to control air supply and exhaust [7]. 

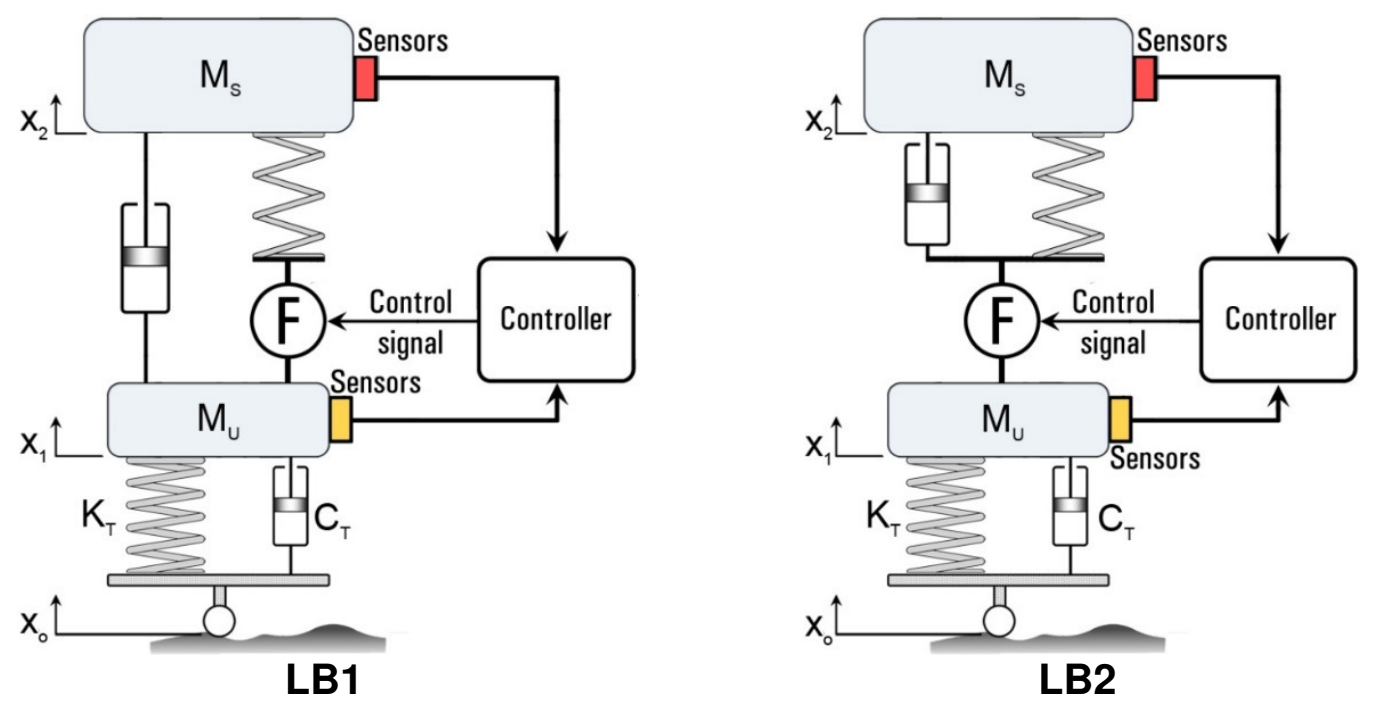

Fig.4. Low bandwidth active suspension system.

Since the actuator only needs a narrow bandwidth, $3-4 \mathrm{~Hz}$, the slow active suspension system can be significantly cheaper than the fully active suspension system in which the broadband actuator is required. But the active control still embraces the normal range of body resonant frequency in bounce, pitch and roll, and the frequency range of interests as far as responses to steering control is concerned. Therefore, the slow active suspension is commercially viable alternative [8].

\section{PDF CONTROLLER OVERVIEW}

The basic idea of the PDF control is to avoid large control signals (which will cause a saturation phenomenon) within the system. For typical step inputs, PID module which contains a differentiator block, gives rise to a sudden high magnitude peak of the system response. To eliminate such a disadvantage, the derivative action is introduced in the feedback path, and improving the response of the system. So in PDF controllers, the system response is highly acceptable, as the set-point kick phenomenon i.e. the generation of an impulse due to the presence of differentiator in the forward path of a conventional PID controller is avoided [9]. Another application for the PDF controller which is applied to an electro-hydraulic elevator. The PDF controller scheme had shown to be an appropriate technique to achieve the desired velocity pattern. Furthermore, this system guarantees low non-synchronous error [10]. By bringing the proportional and derivative control actions to the feedback path, it is possible to choose larger values for $K_{p}$ and $T_{d}$ than those possible by the PID control. So the PDF controlled system will attenuate the effect of disturbance faster than the PID-controlled case. This paper is dedicated to investigate the dynamic performance of active suspension system PID and PDF controllers.

\section{DESCRIPTION OF THE PROPOSED ACTIVE SUSPENSION SYSTEM}

The proposed system as shown in (Fig. 5) consists mainly of electro-hydraulic servo 


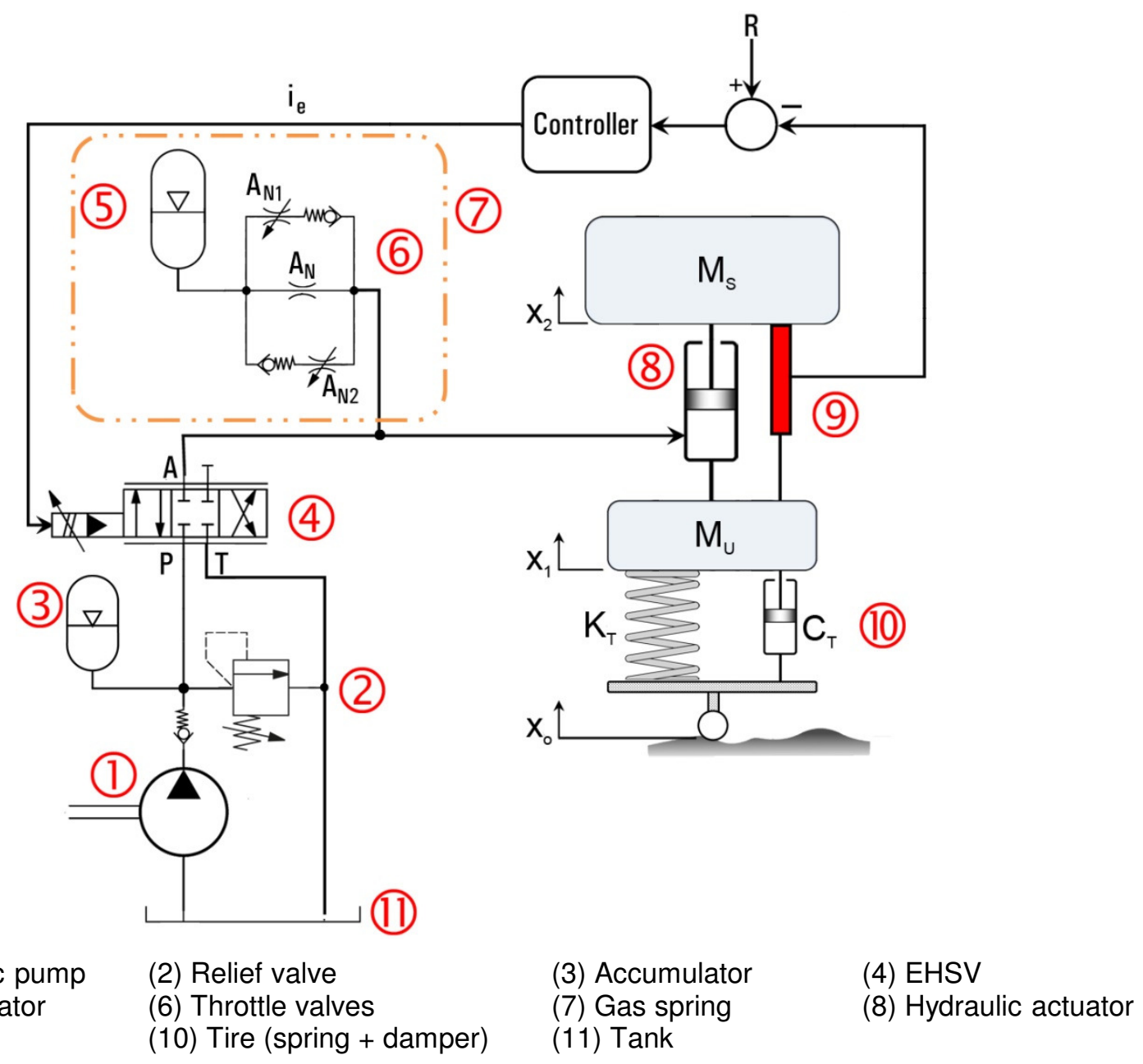

Fig. 5. Schematic diagram of the designed active suspension system.

valve, actuator, air spring, LVDT, and controller [11]. Electro hydraulic actuator is used widely in the design of the active suspensions. The electrohydraulic servo systems provide good control from the point of view of precision and speed.

\section{MATHEMATICAL MODEL OF THE ELECTROHYDRAULIC SERVO-VALVE}

Rabie [12] developed an equivalent mathematical model to the EHSV described by 27 equations. For simplification purpose, the detailed model of the EHSV could not be employed in the full active suspension system model. Because the long time it takes for calculation and iteration process. So, it is important to find the equivalent transfer function for EHSV. For this purpose, the transient response of the actuator displacement to step input current ie, was calculated. It was found that the step response of the spool displacement behaves like an over damped second order system, which can be described by the following transfer function of the second order system.

$$
G(s)=\frac{k}{\left(\frac{1}{\omega_{n}^{2}}\right) s^{2}+\left(\frac{2 \xi}{\omega_{n}}\right) s+1}
$$


The coefficients $k, \omega_{n}$ and $\xi$ of the corresponding representative transfer function are calculated. The gain value $(\mathrm{k})$ is the spool displacement in the steady state conditions divided by the value of excitation current $10 \mathrm{~mA}$. The values of $\omega_{n}$ and $\xi$ are calculated by running a Simulink program. The representative transfer function is obtained in (equation 2).

$$
G(s)=\frac{0.020134}{2 \times 10^{-6} s^{2}+0.0041 s+1}
$$

\section{MATHEMATICAL MODEL OF THE HYDRO-PNEUMATIC SUSPENSION UNIT}

A scheme of hydro-pneumatic suspension unit is shown in (Fig. 2). The mathematical model of the system is developed by applying the equations describing the dynamic behavior of the suspension unit. The following equations are describing this system.

$$
Q_{P}-A_{P}\left(\frac{d x_{1}}{d t}-\frac{d x_{2}}{d t}\right)-\frac{V_{P_{0}}+A_{P} y}{B} \frac{d P_{p}}{d t}=0
$$

where; $\frac{V_{P_{0}}+A_{P} y}{B} \frac{d P_{p}}{d t}$ is a term considering the effect of the compressibility at the piston chamber.

$$
\begin{aligned}
& Q_{a}-Q_{b}-Q_{p}+A_{P}\left(\frac{d x_{1}}{d t}-\frac{d x_{2}}{d t}\right)=\frac{V_{P}-A_{P}\left(x_{1}-x_{2}\right)}{B} \frac{d P_{P}}{d t} \\
& Q_{P}=Q_{P 1}+Q_{P o}+Q_{P 2} \\
& Q_{P 1}=C_{d} A_{N 1} \sqrt{2\left(P_{P}-P_{N}\right) / \rho} \\
& A_{N 1}=\left\{\begin{array}{cll}
0 & \text { for } P_{P}<P_{N} \\
\pi d_{1} z_{c} & \text { for } P_{P} \geq P_{N}
\end{array}\right. \\
& Q_{P o}=C_{d} A_{N} \sqrt{2\left(P_{N}-P_{P}\right) / \rho} \\
& Q_{P 2}=C_{d} A_{N 2} \sqrt{2\left(P_{N}-P_{P}\right) / \rho} \\
& A_{N 2}=\left\{\begin{array}{ccc}
0 & \text { for } P_{p}>P_{N} \\
\pi d_{2} z_{c} & \text { for } P_{p} \leq P_{N}
\end{array}\right.
\end{aligned}
$$

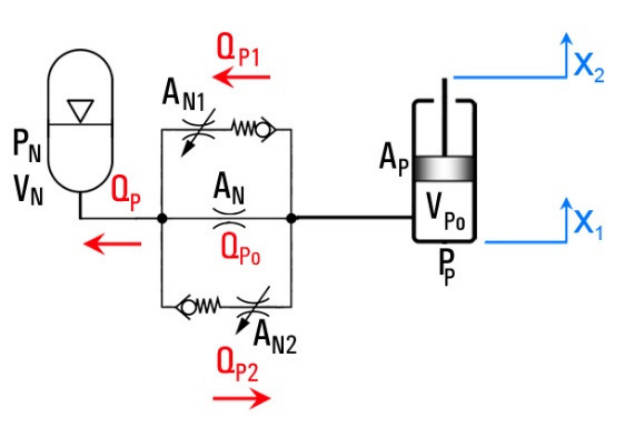

Fig. 6. Schematic drawing of the hydropneumatic suspension.

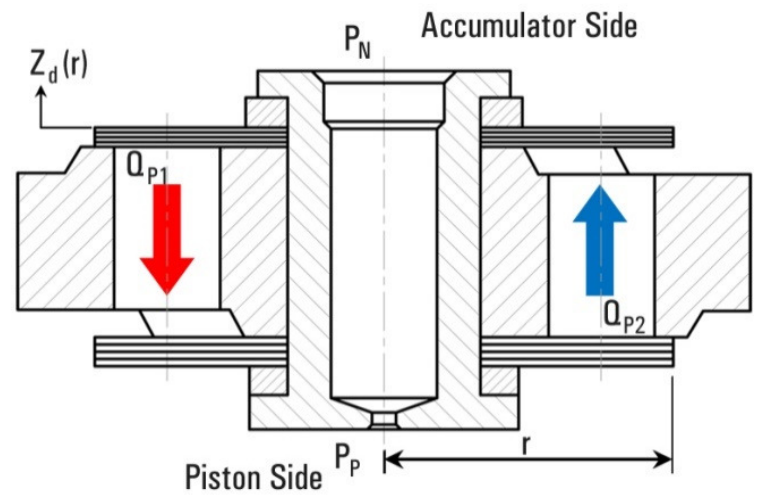

Fig. 7. Damping system valves of the hydro-pneumatic suspension unit. 
The variable orifice areas in the compression and rebound strokes for the damping system are consists of four holes covered with a circular thin plate riveted in its center, (Fig. 6). The dynamics of the thin plate are not considered due to its negligible weights and its small displacement. The deflection of the circular plate, due to the pressure difference, is calculated according to the following equation [11].

$$
\begin{aligned}
& \mathrm{z}_{d}(r)=\left[k_{1} \frac{r^{2}}{2}+k_{2} \ln (r)-\frac{p}{2 D}\left\{\frac{a^{2} r^{2}}{4} \ln (r)-\frac{a^{2} r^{2}}{8}\right\}-\frac{a^{2} r^{2}}{8}-\frac{r^{4}}{32}\right]+k_{3} \\
& V_{N}=V_{N 1}-\int Q_{P} d t \\
& P_{N}=P_{N 1}\left(\frac{V_{N 1}}{V_{N}}\right)^{1.3} \\
& F=P_{P} A_{P}
\end{aligned}
$$

MATHEMATICAL DESCRIPTION OF THE QUARTER-CAR MODEL

$$
\begin{aligned}
& P_{P} A_{P}-M_{S} g-f_{P}\left(\frac{d x_{2}}{d t}-\frac{d x_{1}}{d t}\right)=M_{S} \frac{d^{2} x_{2}}{d t^{2}} \\
& K_{t}\left(x_{1}-x_{0}\right)+C_{t}\left(\frac{d x_{1}}{d t}-\frac{d x_{0}}{d t}\right)-M_{U} g-P_{P} A_{P}-f_{P}\left(\frac{d x_{1}}{d t}-\frac{d x_{2}}{d t}\right)=M_{U} \frac{d^{2} x_{1}}{d t^{2}}
\end{aligned}
$$

\section{QUARTER VEHICLE SUSPENSION PARAMETERS}

The damping coefficient (Cs) of the shock absorber is calculated instantaneously from the validated simulation model of the damper. $F(t)$ is the excitation acting on the wheel and induced by surface irregularities. If $x_{0}$ is the elevation of the surface profile and $\dot{x}_{0}$ represents the vertical velocity of the tire at the ground contact point, which is the slope of the road profile multiplied by the forward speed of the vehicle [13].

\section{DESIGN OF ACTIVE SUSPENSION SYSTEM}

In this section, the output-controlled variables are chosen to achieve the required dynamic response for the vehicle body. The control structure of the measured feedback values is constructed and the measuring devices are determined.

\section{OPERATION OF THE DESIGNED ACTIVE SUSPENSION SYSTEM.}

The operation of the designed active suspension system is divided into three modes; neutral mode, compression mode and rebound mode.

\section{Neutral Position}

When the vehicle is running in a very smooth road or the vehicle is stopped, it means that there is no input displacement from the road, and there is no any relative motion 
between the vehicle body and the wheel assembly. The feedback current from the LVDT and the accelerometer is zero and the error signal (ie) to the servo-valve is zero as shown in (Fig. 5). Therefore, the spool of the EHSV is in the neutral position.

\section{Compression Mode}

If the vehicle is exposed to a bump from the road, the wheel assembly moves upward. And the distance between the vehicle body and the wheel decreased. The feedback current from the LVDT and the accelerometer increased and the error signal (ie) to the servo-valve increased. The pressure $\left(\mathrm{P}_{2}\right)$ increased and the spool moves to the left hand side. The piston chamber is connected partially to the tank to permit the flow of oil, due to the movement of the piston, to be directed to the tank. This nearly keeps the vehicle body in the same level.

\section{Rebound Mode}

In the rebound stroke due to the pothole, the wheel assembly moves downward, the distance between the vehicle body and the wheel assembly increased. As a result, the feedback current increased and the negative error signal (ie) to the EHSV increased. The oil flow increased to the left hand side spool chamber and the pressure $\left(\mathrm{P}_{1}\right)$ increased, therefore the spool moves to the right hand side, the cylinder chamber is connected with the pressure line, the oil flows to the piston chamber to compensate for the out ward motion of the piston, trying to keep the vehicle body in the same level.

\section{SIMULATION OF THE ACTIVE SUSPENSION SYSTEM}

The proposed active vehicle suspension is described mathematically by equations (2) to (16). The electrohydraulic active suspension should be connected in closed loop arrangement to control the vehicle level. Therefore, convenient sensors and amplifier should be used as shown in (Fig. 8).

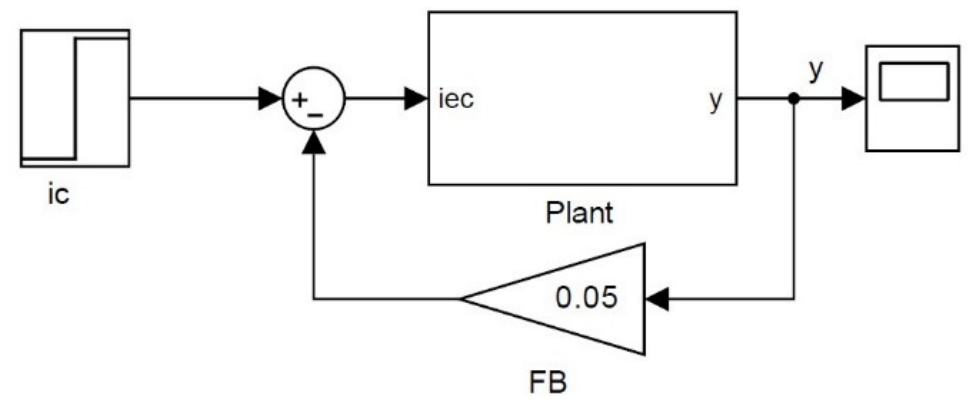

Fig. 8. Active suspension in a closed loop arrangement.

The deduced mathematical model was used to develop a simulation program, using the MATLAB package. The response of the vehicle level to a step input current was calculated and plotted in (Fig. 9). This figure shows that the response is over damped, with no steady state error and $5.26 \mathrm{~s}$ settling time. The obtained value of settling time 
is too long for this class application. Therefore a convenient controller is needed to improve the system performance.

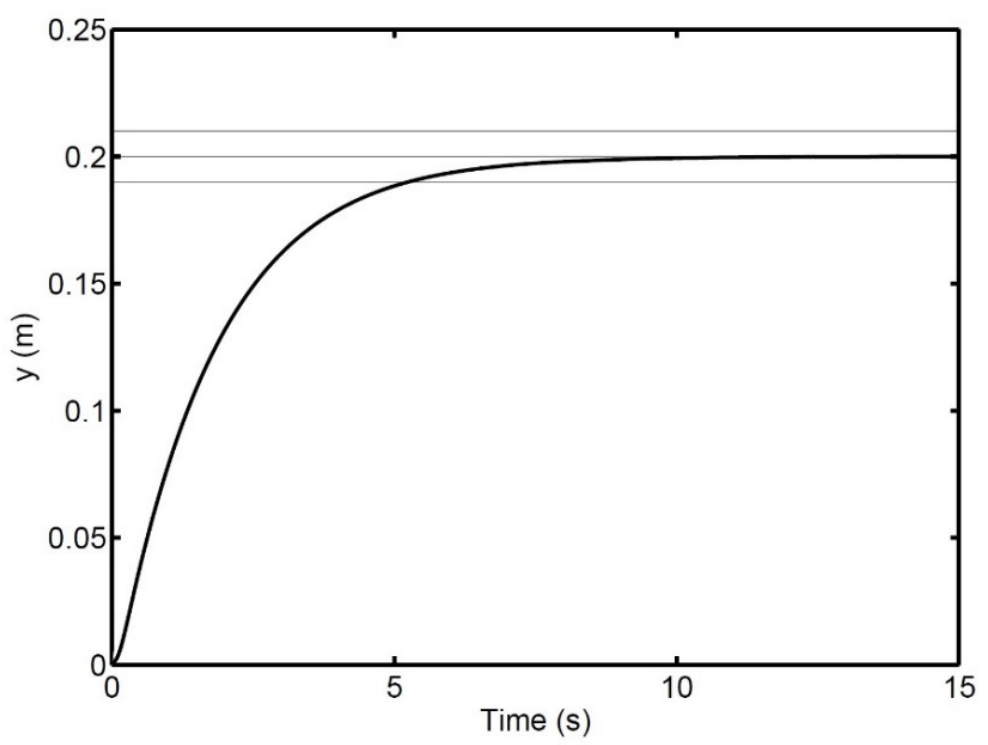

Fig. 9. Step response of the level control to a step input current of $10 \mathrm{~mA}$.

\section{DESIGN OF PID CONTROLLER}

A proportional-integral-derivative controller (PID controller) is a generic control loop feedback mechanism (controller) widely used in industrial control systems. A PID controller calculates an "error" value as the difference between a measured output value and a desired set point. The controller attempts to minimize the error by adjusting the actual plant control inputs.

The PID controller calculation algorithm involves three separate constant parameters, and is accordingly sometimes called three-term control: the proportional, the integral and derivative values, denoted P, I, and D, (Fig. 10). The proportional term $P$ depends on the present error, the integral term I depends on the accumulation of past errors, and the derivative term $D$ is a prediction of future errors, based on current rate of change. The weighted sum of these three actions is used to adjust the plant or process via a control element such as the position of a control valve or a damper.

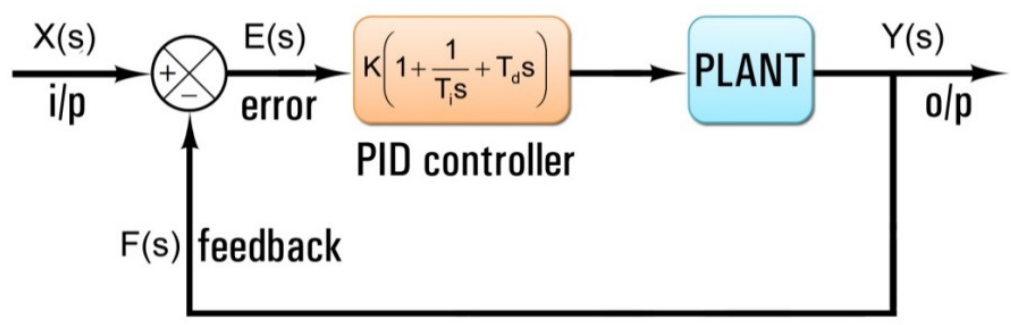

Fig. 10. Connection of the PID controller in the closed loop system. 
The process of selecting the controller parameters to meet given performance specifications is known as controller tuning. Ziegler and Nichols suggested rules for tuning PID controllers (meaning to set values $\mathrm{K}_{\mathrm{p}}, \mathrm{T}_{d}$ and $\mathrm{T}_{i}$ ) based on experimental step responses or based on the value of $\mathrm{Ku}$, that results in marginal stability when only proportional control action is used. Ziegler-Nichols rules are useful when mathematical models of plants are not known. Such rules suggest a set of values of $K_{p}, T_{d}$ and $T_{i}$, that will give a stable operation of the system. However, the resulting system may exhibit a large maximum overshoot in the step response, which is unacceptable. In such a case we need series of fine tunings until an acceptable result is obtained. In fact, the Ziegler-Nichols tuning rules give an educated guess for the parameter values and provide a starting point for fine tuning, rather than giving the final settings for $K_{p}$, $\mathrm{T}_{\mathrm{i}}$, and $\mathrm{T}_{\mathrm{d}}$, in a single shot. There are two methods called Ziegler-Nichols tuning rules: the first method and the second method.

Herein, a PID controller was used in this study. A first estimate of the PID controller parameters was carried out according to the first Ziegler-Nichols method [14]. Furthermore, a fine-tuning process was carried out manually to find the parameters of the controller; $\mathrm{K}, \mathrm{T}_{\mathrm{i}}$ and $\mathrm{T}_{\mathrm{d}}$, which results in a minimum value of the Integral of time absolute error performance index; ITAE, defined as follows:

$$
\operatorname{ITAE}=\int_{0}^{\infty} t|e(t)| d t
$$

Some applications may require using only one or two actions to provide the appropriate system control. This is achieved by setting the other parameters to zero. A PID controller will be called a PI, PD, P or I controller in the absence of the respective control actions. PI controllers are fairly common, since derivative action is sensitive to measurement noise. The constants of the controllers were calculated and finely tuned. The step response of the system with proportional controller shows that the implementation of a proper proportional controller reduced the settling time from 5.26 $\mathrm{s}$ to $0.65 \mathrm{~s}$. However, this conclusion can't be generalized. The proportional controller is associated with non-negligible steady state error unless the plant incorporates an integrating element. The studied plant includes a hydraulic cylinder which acts as an integrating element when controlling the displacement or level.

The response of the studied active suspension system was calculated. The calculation results are plotted in (Fig. 11). The settling time and maximum percentage overshoot, found out from the plotted simulation results are stated in (Table 1). These results showed that the PID controller gives the best results, mainly on the level of the settling time. And the PD controller gives the minimum maximum percentage overshoot.

Derivative action predicts system behavior and thus improves settling time and stability of the system. Derivative action, however, is seldom used in practice because of its inherent sensitivity to measurement noise. If this noise is severe enough, the derivative action will be erratic and actually degrade control performance. Large, sudden changes in the measured error (which typically occur when the set point is changed) cause a sudden, large control action stemming from the derivative term, which goes under the name of derivative kick. This problem can be ameliorated to a degree if the measured error is passed through a linear low-pass filter or a nonlinear but simple median filter [15]. 


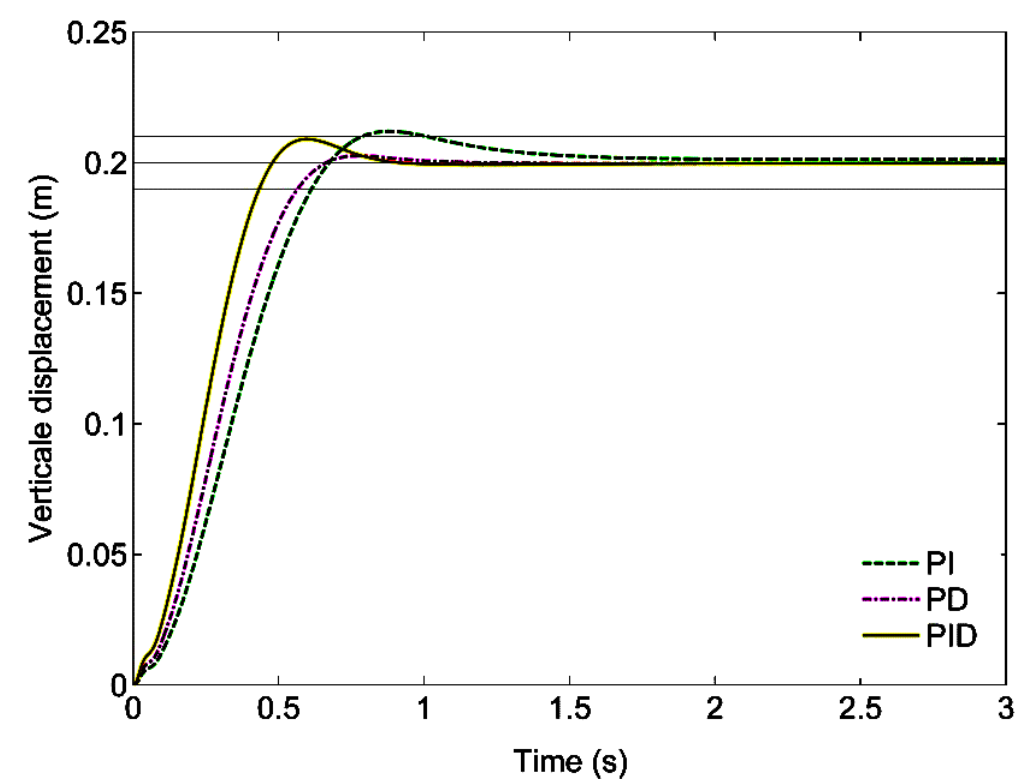

Table 1. Main characterizing parameters of active suspensions with diverse controllers.

\begin{tabular}{c|c|c}
\hline Controller & $\boldsymbol{\sigma}(\%)$ & $\begin{array}{c}\mathbf{T}_{\mathbf{s}} \\
(\mathbf{s})\end{array}$ \\
\hline PI & 6 & 0.617 \\
PD & 1.3 & 0.566 \\
PID & 4.5 & 0.434 \\
PDF & 0.45 & 0.455 \\
\hline \hline
\end{tabular}

Fig. 11. Transient response of the active suspension equipped with I, PI, PD and PID controllers, to a step input current of $10 \mathrm{~mA}$.

The PI controllers are common, since derivative action is sensitive to measurement noise. But the power of this controller did not appear here due to the inclusion of an integrating element in the investigated active suspension.

\section{DESIGN OF PDF CONTROLLER}

Phelan [16] proposed a set of formulae for estimating a first approximation of the controller gain constants; $\mathrm{K}_{\mathrm{p}}, \mathrm{K}_{\mathrm{D}}$, and $\mathrm{K}_{\mathrm{i}}$, from which the fine tuning commences. These formulae are combination of analytical and experimental results. These formulae are based upon the maximum step input for which an essentially linear output response is required. When the system is represented by a transfer function of the form:

$$
\mathrm{G}(\mathrm{s})=\frac{1}{\mathrm{sB}_{\mathrm{c}}(\mathrm{Ts}+1)}
$$

So that, the development of the PDF controller necessitates the representation of the system, open loop, by means of a transfer function of first or second order [17]. For this purpose, the transient response of the system to step input current, $i$, was calculated for different magnitudes of the applied step. The active suspension system presented step responses apparently similar to that of a second order element whose transfer function is given by (19):

$$
G(s)=\frac{740}{s^{2}+14.4 s+1}
$$

The step response of the system with proportional feedback is calculated using the detailed model and the equivalent transfer functions. The calculation results are plotted 
in (Fig. 12), which shows good agreement between the transient behaviors of the two models.

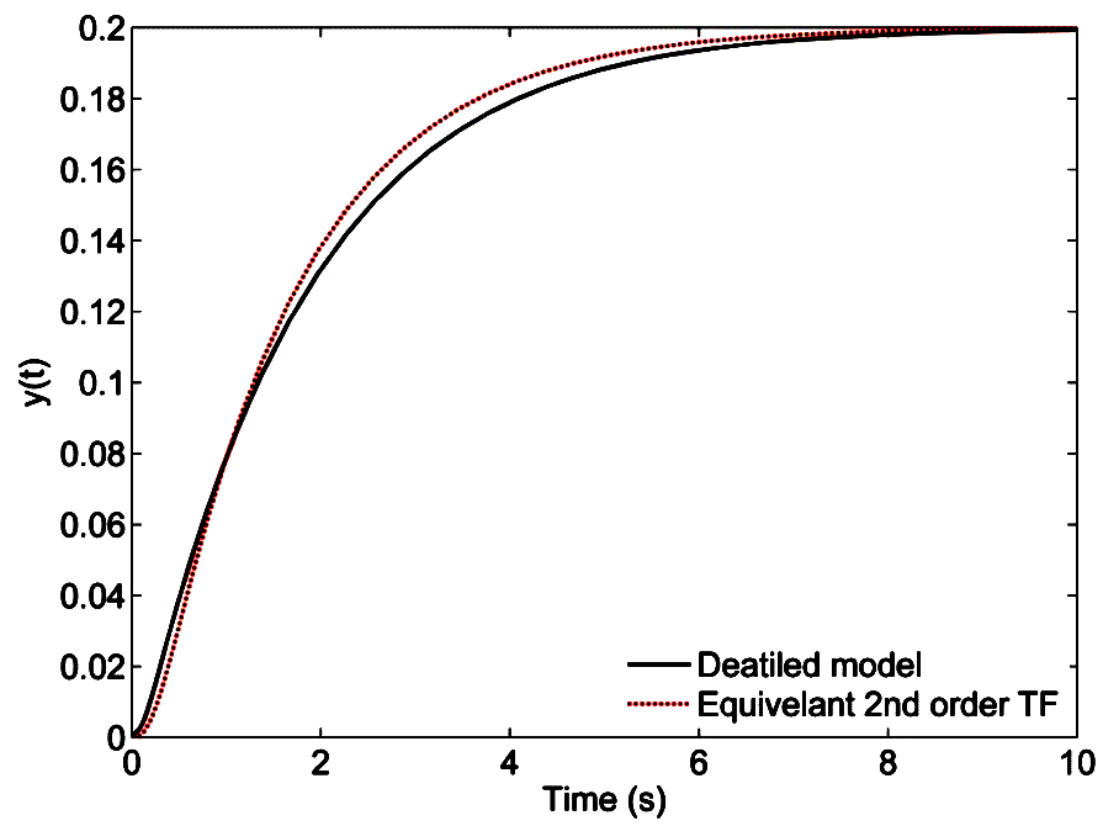

Fig. 12. Step response of active suspension system and equivalent representative model.

Equations from (20) to (22) are used to calculate a first approximation of the PDF controller constants. The tuning of the PDF controller is carried out by finding the best combination of the coefficients $K_{p}, K_{D}, K_{i n}$ to provide the optimum system response.

$$
\begin{aligned}
& \mathrm{K}_{\mathrm{P}}=\frac{8 \mathrm{~m}}{\mathrm{j}} \\
& \mathrm{K}_{\mathrm{D}}=1.414 \sqrt{\mathrm{B}_{\mathrm{c}} \mathrm{T}_{\mathrm{S}} \mathrm{K}_{\mathrm{P}}}-\mathrm{B}_{\mathrm{c}} \\
& \mathrm{K}_{\text {in }}=0.2828 \sqrt{\frac{\mathrm{K}_{\mathrm{P}}^{3}}{\mathrm{~B}_{\mathrm{c}} \mathrm{T}_{\mathrm{S}}}}
\end{aligned}
$$

\section{RESULTS}

The designed model program for quarter vehicle utilizing active suspension is used to investigate the level control between the sprung and the unsprung masses. The controllers which are implemented in this investigation are PI, PD, PID, and PDF controllers. Two criterions are used to tune the parameters of the controllers manually. Integral of square error (ISE) and integral time of absolute error (ITAE) are used each separately to tune the controllers. Active suspension system results could be summarized as following.

- Studying the transient response of vehicle level to step input current for different controllers with minimized ISE criterion.

- Studying the transient response of vehicle level to step input current for different controllers with minimized ITAE criterion. 


\section{STEP RESPONSE OF VEHICLE LEVEL WITH TUNED PARAMETERS FOR MINIMUM ISE CRITERION}

The transient response of the vehicle level to a step input current $10 \mathrm{~mA}$ was calculated using a quarter vehicle model incorporating the pre-described active suspension. The quarter vehicle was equipped with PI, PD, PID, or PDF controllers. The parameters of the PID controllers were estimated using the second method of Ziegler-Nicholas. All of the controller's parameters were manually finely tuned to minimize the Integral of the squared error (ISE). The calculation results are plotted from (Fig. 13).

This results showed that the PD presented the shortest settling time $(0.33 \mathrm{~s})$ while the $\mathrm{PI}, \mathrm{PID}$, and PDF presented settling time of $1.36 \mathrm{~s}, 0.51 \mathrm{~s}$, and $0.7 \mathrm{~s}$ respectively.

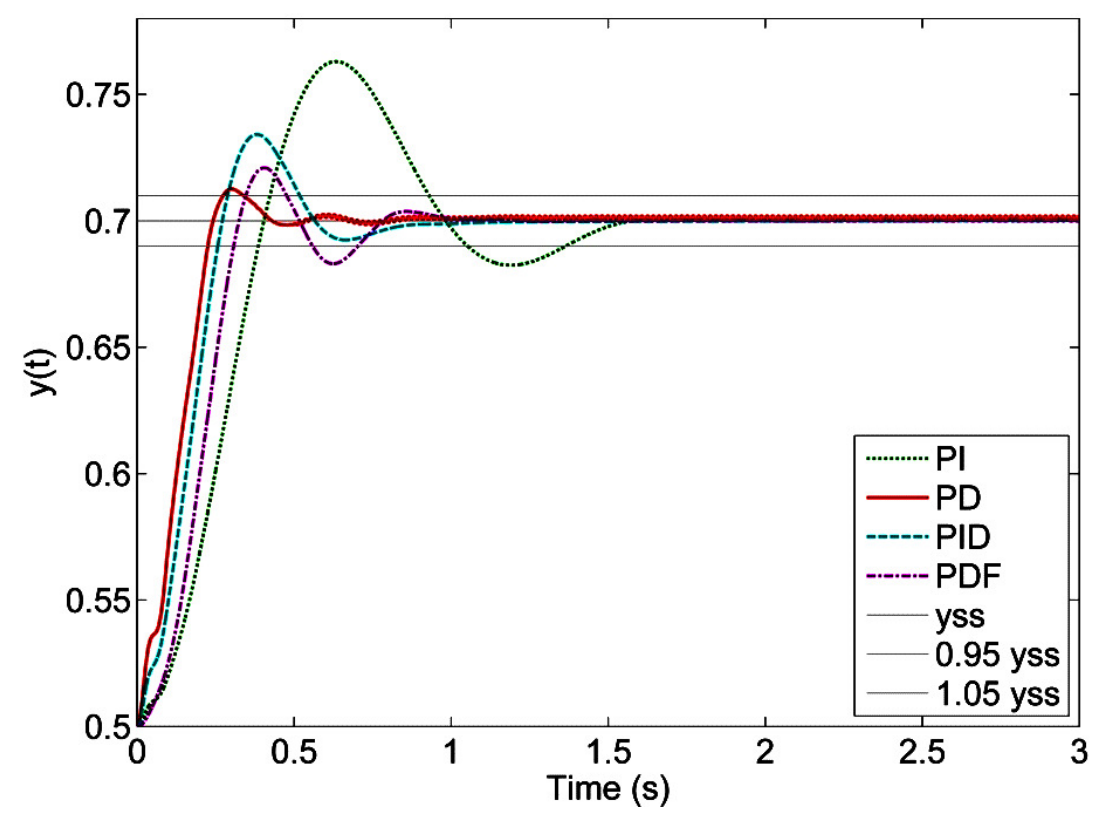

Fig. 13. Step response of actuator due to input current of $10 \mathrm{~mA}$ for different tuned controllers based on ISE criterion.

\section{STEP RESPONSE OF VEHICLE LEVEL WITH TUNED PARAMETERS FOR MINIMUM ITAE CRITERION}

The response of the vehicle level was calculated to step input of $10 \mathrm{~mA}$ considering the manually fine tuning of the controller's parameters to minimize the integral of time absolute error (ITAE) criterion (Fig. 14). These results showed that the shortest settling time is obtained when using either the PID or the PDF controllers. The PDF controller showed negligible maximum percentage overshoot. While the PID showed a maximum percentage, overshoot within 5\%. The PI and PD showed longer settling time $0.55 \mathrm{~s}$, $0.62 \mathrm{~s}$ respectively.

\section{RESPONSE OF VEHICLE LEVEL DUE TO STEP ROAD INPUT}

The response of the vehicle level to a step road input was calculated for constant 


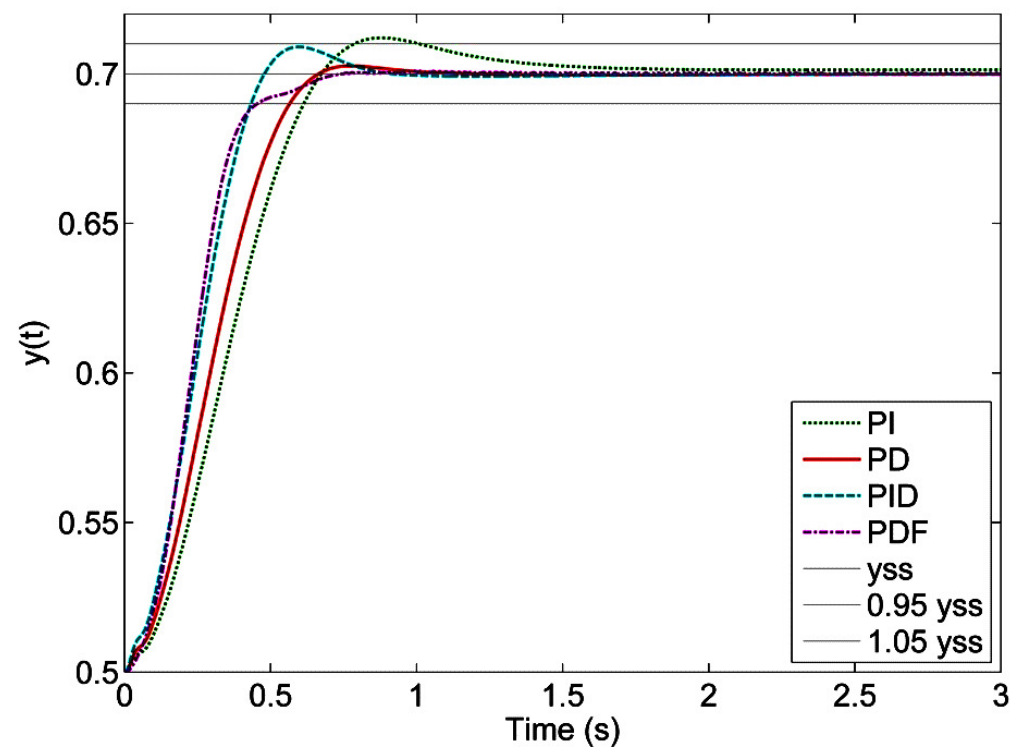

Fig. 14. Step response of actuator due to input current of $10 \mathrm{~mA}$ for different tuned controllers based on ITAE criterion.

control current and step road input. The suspension was equipped with PI, PD, PID, or PDF controllers, manually fine-tuned to minimize the ITAE criterion. The calculation results are plotted from (Fig. 15). The PDF controller showed the shortest settling time $(0.14 \mathrm{~s})$ followed by the PID (0.33 s).

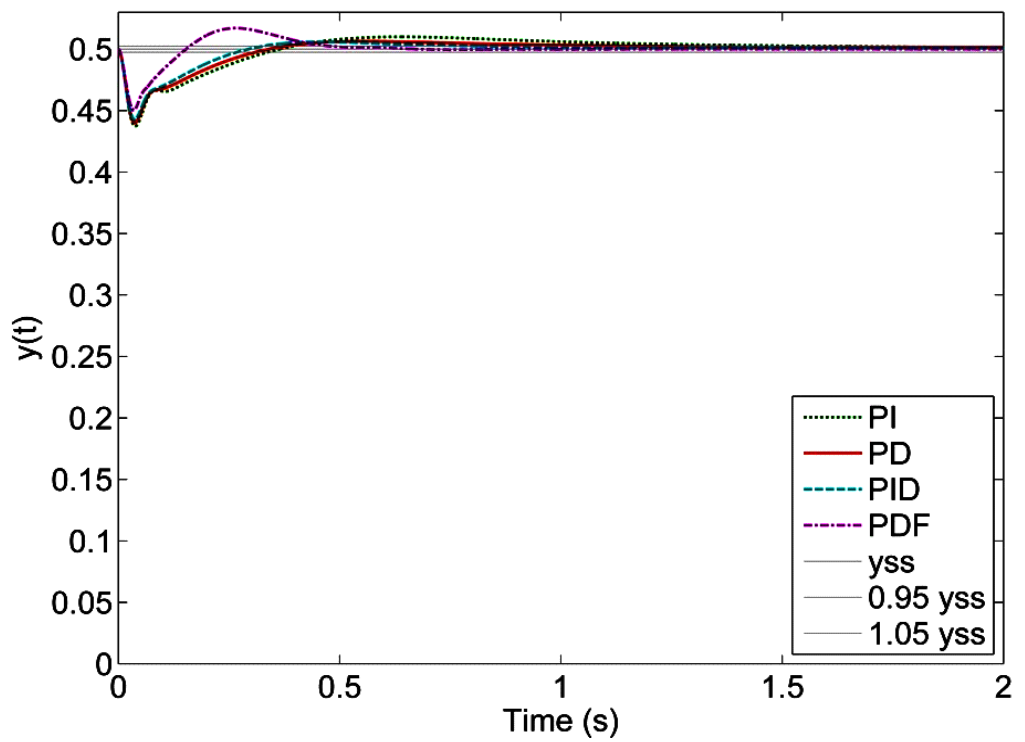

Fig. 15. Response of actuator due to road step input of $5 \mathrm{~cm}$ for different controllers.

\section{CONCLUSION}

A design for quarter vehicle equipped with active suspension system is presented. This design included hydraulic pump, two stage electrohydraulic servo-valve, actuator, and hydro-pneumatic suspension unit. PI, PD, PID, and PDF controllers are alternatively employed in the designed active suspension system. Mathematical models describing the dynamic behavior of the studied system were deduces $d$ and used to develop 
SIMULINK simulation programs. The transient response of level control of the active suspension system was calculated using the simulation program. The controller parameters were finely manually tuned separately to minimize the ISE and ITAE error criterions. The study of the calculated response showed the following.

The transient response of the vehicle level was calculated to step input of $10 \mathrm{~mA}$ for different controllers, finely tuned to minimize the ISE, showed that the PD presented the shortest settling time $(0.33 \mathrm{~s})$ while the PI, PID, and PDF presented settling time of $1.36 \mathrm{~s}, 0.51 \mathrm{~s}$ and $0.7 \mathrm{~s}$ respectively.

The transient response of the vehicle level was calculated to step input of $10 \mathrm{~mA}$ for different controllers, finely tuned to minimize the ITAE. The simulation results showed that the shortest settling time is obtained when using either the PID or the PDF controllers. The PDF controller showed negligible maximum percentage overshoot. While the PID showed a maximum percentage overshoot within $5 \%$. The PI and PD showed longer settling time $0.55 \mathrm{~s}$ and $0.62 \mathrm{~s}$ respectively.

The response of the vehicle level to a step road input was calculated for constant control current and step road input. The suspension was equipped with PI, PD, PID, or PDF controllers, manually fine-tuned to minimize the ITAE criterion. The PDF controller showed the shortest settling time $(0.14 \mathrm{~s})$ followed by the PID (0.33 s).

\section{RECOMMENDATION FOR FUTURE WORK}

- Investigation of the half car and full car models of the vehicle equipped with the passive suspension and evaluation the vehicle stability and passenger comfort.

- Evaluation of the validity of the simulation program of the proposed active suspension.

- Investigation of the half car and full car models of the vehicle equipped with the active suspension and evaluation the vehicle stability, passenger comfort and selection of the proper controller accordingly.

\section{REFERENCES}

[1] Williams R. A., Best A., and Crawford I. L, "Refined Low Frequency Active Suspension", In International Conference on Vehicle Ride and Handling, paper C466/028/93, 1993, pp. 285-300.

[2] Simon D. E., "Experimental Evaluation of Semiactive Magnetorheological Primary Suspensions for Heavy Truck Applications", MSc. Thesis, Virginia Polytechnic Institute and State University, USA.

[3] Satoh M., Naoto F., Yousuke A., Itaru F., and Kensuke F., "An active suspension employing an electrohydraulic pressure control system", In Decision and Control, Proceedings of $29^{\text {th }}$ IEEE Conference, pp. 2226-2231.

[4] Williams R. A., "Automotive active suspension (Part 1: basic principles), and (Part 2: practical consideration)", Proceedings of the Institution of Mechanical Engineers, Vol. 211, Part D: Journal of Automobile Engineering, June, 1997, pp. 415-426, and pp.427-444. 
[5] Cambridge University, Engineering Department website, March 2014, http://www-control.eng.cam.ac.uk/gww/what_is_active.html.

[6] Sharp R.S., and Crolla, D.A., "Road Vehicle Suspension Design - a Review", Vehicle System Dynamics, Vol. 16 (3), 1987, pp. 167-192.

[7] Wendel, G. R. and Stecklein, G. L., "A regenerative active suspension system", SAE special publication No. 910659, 1991, pp. 129-135.

[8] Shuttlewood D. W., Crolla D. A., R.S. Sharp, "Theoretical Results of an Electrically Actuated Hydro-pneumatic Slow-active Suspension", In Active Suspension Technology for Automotive and Railway Applications (Digest No: 1992/193), IEE Colloquium on, pp. 10-1.

[9] Mazumder S., and Susovan D., "Analytical study and Designing of a I-PD controller (a practical Modified PID controller) for a third order system using MATLAB simulation", International Journal of Engineering Research and General Science Volume 3, Issue 1, February 2015, pp. 976-980.

[10] Li K., Mannan M. A., Mingqian X., and Ziyuan X., 2001, "Electro-hydraulic proportional control of twin-cylinder hydraulic elevators", Control Engineering Practice 9, No. 4, pp. 367-373.

[11] Ziad A. I., 2006, "Design and Analysis of Active Vehicle Suspension Systems", $\mathrm{PhD}$. Thesis, Military Technical College, Cairo, Egypt.

[12] Rabie M. G., "Improvement of Performance an Electrohydraulic Servo Actuator by Developing A PSEUDO Derivative Controller", Modelling, Measurement \& Control, B, ASME Press Vol. 54, No. 3, 1994, pp. 9-23.

[13] Wong J.Y., "Theory of ground vehicles", second edition, Wiley, New York, 1993.

[14] Ogata K., 2010, Modern Control Engineering, $4^{\text {th }}$ edition, Prentice-Hall Inc., New Jersey.

[15] Ang K. H., Gregory C., and Yun L., 2005, "PID control system analysis, design, and technology", Control Systems Technology, IEEE Transactions, No. 4, pp. 559-576

[16] Phelan R. M., 1977, "Feedback Control Systems", Cornell University Press, Ithaca, NY, USA.

[17] Flower, J. O., and Sparrius J. R., 1986, "The design of autopilots using the pseudo-derivative feedback algorithm", International shipbuilding progress 33 , No. 377 , pp. $10-20$ 